\title{
CONTROLE DE DOENÇAS FÚNGICAS E DE DANOS POR FRIO EM PÓS-COLHEITA DE LIMA ÁCIDA TAHITI
}

\author{
L.M. do Nascimento'; P.C. dos Santos ${ }^{2}$ \\ ${ }^{1}$ Instituto Agronômico, Centro de Citricultura "Sylvio Moreira", CP 4, CEP 13490-970, Cordeirópolis, SP, \\ Brasil. E-mail: lenice@centrodecitricultura.br
}

\section{RESUMO}

\begin{abstract}
A lima ácida Tahiti apresenta-se muito susceptível ao ataque de doenças pós-colheita e, também, por sua elevada sensibilidade, ao armazenamento em baixas temperaturas. Com a finalidade de reduzir estes danos, este trabalho objetivou verificar a eficiência do tratamento térmico na desinfestação de patógenos e na prevenção de danos por frio na pós-colheita deste cultivar e comparar este tratamento com outros utilizando os fungicidas convencionais. Os tratamentos térmicos estudados foram com água quente variando as temperaturas entre 48 a $56^{\circ} \mathrm{C}$. A testemunha consistiu de tratamento com água em temperatura ambiente. Depois de tratados, os frutos foram divididos em dois lotes e mantidos em câmara fria com temperatura de $10^{\circ} \mathrm{C}$ e UR de $90 \%$, por aproximadamente 45 dias. Para comparação foram feitos três outros tratamentos simultaneamente: um utilizando imazalil, outro com bicarbonato de sódio e o terceiro com carbonato de sódio, sendo as aplicações destes três produtos feitas em banhos com água em temperatura ambiente. Foram avaliados 2 grupos de frutos, um tratado por imersão considerando os patógenos oriundos do campo, e outro por inoculação com esporos dos fungos previamente isolados. Os parâmetros físico-químicos dos frutos avaliados foram a coloração da casca, a textura, a perda de massa, o tamanho, o rendimento de suco, de sólidos solúveis, o ${ }^{\circ}$ brix, o ratio, a acidez total e a vitamina C. A determinação da sensibilidade dos frutos ao frio foi feita pela exposição deles a temperaturas indutoras de dano por frio. O delineamento experimental utilizado foi blocos ao acaso, com nove tratamentos, analisado pelo pacote estatístico Statgraphics. Verificram-se que os tratamentos térmicos, principalmente a $52^{\circ} \mathrm{C}$, mostraram-se mais promissores no controle de fungos patogênicos e de danos por frio, superando os resultados obtidos nos tratamentos com fungicidas convencionais. Não se verificaram-se alterações dos parâmetros intrínsecos e extrínsecos em função da aplicação dos diferentes tratamentos.
\end{abstract}

PALAVRAS-CHAVE: Citros, termoterapia, armazenamento.

\section{ABSTRACT}

CONTROL OF FUNGAL DISEASES AND CHILLING INJURY IN POST-HARVEST TAHITI LIME. The Tahiti lime appears very susceptible to attack by post-harvest diseases, primarily by the fungi Penicillium and Phomopsis, and also because of its high sensitivity to storage at low temperatures. In order to reduce such damage, the present study aimed to verify the efficiency of heat treatment and disinfection of pathogens in the prevention of post-harvest chilling injury of this cultivar and to compare this treatment with other products using the conventional fungicides. The heat treatments were studied with hot-water temperatures ranging between 48 and $56^{\circ} \mathrm{C}$. Water at room temperature was used as a control treatment. After treatment, the fruits were kept under cold temperature at $10^{\circ} \mathrm{C}$ and $\mathrm{RH} 90 \%$ for about 45 days. For comparison, three other treatments were carried out simultaneously, one using imazalil, one with baking soda, and a third with sodium carbonate, these three products being applied by baths in cold water. Two groups of fruit were evaluated, one treated by immersion considering pathogens coming from the field and another by inoculation with spores of the previously isolated pathogens. For the evaluation of physical and chemical parameters of fruits, determinations were made of the skin color, texture, weight loss, size, juice yield, soluble solids, total acidity and vitamin C content. The determination of the sensitivity of the fruit to cold was made by their exposure at temperatures inducing cold damage. The design was a randomized block design with nine treatments, analyzed by the Statgraphics statistical package. Heat treatments, especially at $52^{\circ} \mathrm{C}$, were shown to be more promising in the

${ }^{2}$ Universidade Estadual Paulista, Ilha Solteira, SP, Brasil. 
control of pathogenic fungi and cold damage, surpassing the conventional fungicides. No changes were found in the intrinsic and extrinsic parameters in relation to the application of the different treatments.

KEY WORDS: Citrus, thermotherapy, storage.

\section{INTRODUÇÃO}

Embora o Brasil seja um dos maiores produtores e exportadores mundiais de limas ácidas Tahiti, atualmente exporta apenas uma pequena parcela dessa produção. A exportação gira em torno de $5 \%$, devido à falta de qualidade dos frutos, principalmente com relação à rápida perda da coloração verde da casca, que tende ao amarelecimento depois da colheita. Isso limita a abertura de novos mercados internacionais pelos produtores brasileiros desse cultivar.

A pós-colheita desses frutos também se vê limitada pelo aparecimento de alterações fisiológicas e pelo ataque de patógenos, que depreciam o valor comercial dos produtos e é a causa de importantes perdas econômicas (Pozzan, 1997).

A forma de se controlar as principais doenças pós-colheita de citros tem sido mediante o emprego de fungicidas de sínteses, por sua fácil aplicação, seu preço e sua efetividade. Apesar de tudo, seu uso prolongado, e muitas vezes descontrolado, tem gerado uma série de problemas, tais como o aparecimento de cepas de patógenos resistentes à ação dos fungicidas e a presença de resíduos na superfície da fruta, além da contaminação ambiental. Com isso, surgem pesquisas direcionadas para a busca de novas opções de tecnologias e de novos produtos que sejam efetivos e, ao mesmo tempo, sejam utilizados de forma respeitosa ao meio ambiente (NASCIMENTO et al., 2005).

Os frutos de limas ácidas Tahiti apresentam grande sensibilidade à estocagem a frio (chilling injury), cujos sintomas se desenvolvem durante o armazenamento em temperaturas inferiores a $8^{\circ} \mathrm{C}$. Esta sensibilidade pode ocasionar sérias implicações econômicas quando o tratamento é realizado inadequadamente. A conservação frigorifícada é também considerada o método mais eficaz para preservar a qualidade dos frutos, uma vez que retarda seu envelhecimento, diminui a respiração, a maturação, a incidência de podridões e as trocas metabólicas indesejáveis (CUQuerella; NAVARro, 1989).

Para minimizar o aparecimento de sintomas de danos de frio, vêm sendo utilizados tratamentos com o uso de calor, com a finalidade de induzir maior tolerância ao frio pelos frutos. Os tratamentos pós-colheita de citros por elevação da temperatura também são desejáveis por serem meios não químicos utilizados para a desinfestação de patógenos que normalmente se manifestam após os frutos colhidos. Segundo Chitarra; Chitarra (2005), a habilidade das frutas de adquirirem tolerância às temperaturas usualmente danosas pode mudar, se estas forem submetidas a um tratamento de aquecimento gradual, evitando dessa forma o comprometimento dos tecidos em decorrência do calor excessivo.

Segundo alguns autores, os tratamentos térmicos foram utilizados no passado como meio de controlar as podridões pós-colheita, antes do desenvolvimento de fungicidas de sínteses, como o tiabendazol e o imazalil (GRIERSON; BEN-YeHOSHUA, 1986). As recentes exigências de redução do uso de fungicidas de sínteses, o desenvolvimento de resistências a tais fungicidas e o aumento dos custos para o desenvolvimento de novos fungicidas vêm aumentando a opção de recuperar o emprego de tratamentos térmicos como um procedimento respeitoso com o meio ambiente no controle de podridões. Em alguns laboratórios, vêm-se desenvolvendo com êxito diversos métodos com aplicação de calor de larga ou curta duração. A cura dos frutos durante 72 horas a $36^{\circ} \mathrm{C}$ ou uma rápida ducha no drencher ou na balsa com água quente tem proporcionado resultados satisfatórios em diversas variedades de citros (BEN-YEHOSHUA et al., 1989; Ben-Yehoshua et al., 1995; Ben-Yehoshua et al., 1997).

A proposta deste trabalho foi verificar a eficiência do tratamento térmico como forma respeitosa ao meio ambiente na desinfestação de patógenos e na prevenção de danos por frio, na pós-colheita de limas ácidas Tahiti e comparar os mesmos tratamentos com outros utilizando os produtos fungicidas convencionais.

\section{MATERIAL E MÉTODOS}

Limas ácidas Tahiti, colhidas em pomares comerciais, foram transportadas aos laboratórios do Centro de Citricultura "Sylvio Moreira", do Instituto Agronômico de Campinas (IAC), localizado no Município de Cordeirópolis, SP, onde passaram por uma seleção prévia, retirando-se os frutos com defeitos fisiológicos e mecânicos e com sintomas de doenças. Em seguida, foram instalados 2 experimentos simultaneamente a fim de confrontar os resultados de um com o outro.

Os tratamentos térmicos estudados foram realizados com água quente variando as temperaturas em mais ou menos $1^{\circ} \mathrm{C}$, ou seja: $48,50,52,54$ e $56^{\circ}$ $\mathrm{C}$, e considerando os patógenos oriundos do campo. Como testemunha utilizou-se um tratamento com 
água em temperatura ambiente. Os frutos foram imersos nas temperaturas supracitadas por um tempo de 2 minutos. Os frutos depois de tratados foram acondicionados em caixas de papelão com capacidade para $18 \mathrm{~kg}$ e mantidos em câmara fria a $10^{\circ} \mathrm{C}$ e umidade relativa de $90 \%$.

Para avaliar a eficiência dos tratamentos térmicos no controle de patógenos e comparar os resultados com outros métodos de controle, foram realizados um tratamento químico e dois outros alternativos, concomitantemente. Como tratamento químico utilizou-se o fungicida imazalil, em dose comercialmente recomendada e, como alternativa, o bicarbonato de sódio e o carbonato de sódio, em soluções a 3\%. As aplicações de imazalil, de bicarbonato e carbonato de sódio foram feitas em banhos deágua em temperatura ambiente. Foram avaliados também frutos inoculados com esporos de fungos previamente isolados e frutos não inoculados, nos quais se consideraram as infecções oriundas do campo (imersão).

Para os estudos de controle de podridões por métodos físicos (água quente e produtos químicos) foram utilizados frutos inoculados, sendo 18 frutos por repetição. A inoculação dos frutos foi realizada por ferimentos, simulando os decorrentes daqueles causados pela pressão de objetos cortantes, tais como espinhos ou pedúnculos grandes. Os ferimentos foram feitos em dois pontos na região equatorial e em lados opostos, utilizando-se pontas metálicas de $10 \mathrm{~mm}$ de profundidade e aproximadamente $0,8 \mathrm{~mm}$ de diâmetro. Foram inoculadas suspensões de esporos de Penicillium digitatum e Geotrichum candidum, nas concentrações de $10^{4}$ conídios/mL Os frutos, uma vez tratados, foram acondicionados em caixas plásticas com tampa e armazenados em câmara fria a $10^{\circ} \mathrm{C}$ e $90 \%$ de UR. Os frutos, que expressaram os sintomas característicos das podridões causadas pelos fungos inoculados, tiveram as lesões medidas com paquímetro digital, durante 5 dias consecutivos, considerando o desenvolvimento da infecção do ápice para o pedúnculo.

\section{Determinação das característicasfísico-químicas}

Para avaliação da qualidade interna e externa dos frutos foram retiradas, quinzenalmente até o final de cada experimento, três amostras de seis frutos de cada tratamento e determinadas a coloração da casca e as características físico-químicas. As avaliações de coloração da casca e polpa foram feitas com colorímetro Minolta, expressando-se os resultados por um índice de coloração da casca e da polpa (IC). As determinações de altura e diâmetro do fruto foram feitas por leitura direta de cada amostra, com auxílio de uma escala graduada em centímetros. A massa total dos frutos de cada amostra foi obtida, de uma só vez, em uma balança com capacidade de até $15 \mathrm{~kg}$. Orendimento de suco foi determinado após esmagamento do fruto em extratora, sendo calculado pela relação massa do suco/massa do fruto e expresso em porcentagem. Oteor de sólidos solúveis (SS ou ${ }^{\circ}$ BRIX) foi determinado por leitura direta ao refratômetro, sendo os dados corrigidos pela leitura e pela acidez do suco. A vitamina $C$ foi quantificada segundo o método descrito por RedD et al. (1986). A acidez total (AT) foi obtida por titulação em uma solução de hidróxido de sódio usando-se fenolftaleína como indicador. Calculou-se a relação sólidos solúveis/ acidez total (ratio ou ST/AT), considerando-se o valor da acidez igual a 1. O índice tecnológico (IT) foi calculado segundo o método de Di GIORGI et al. (1990). Avaliou-se também a desidratação dos frutos, através das perdas de massa de uma amostra isolada com três repetições de todos os tratamentos. As perdas de massa foram contabilizadas expressando-se os resultados em porcentagem, e a textura medida utilizando-se penetrômetro digital.

Determinação da sensibilidade dos frutos ao frio após os tratamentos térmicos e químicos, em tratamentos de quarentena por frio e em conservação frigorifícada

Os frutos foram expostos, por um tempo variável, a temperaturas indutoras de dano por frio, em torno de $2^{\circ} \mathrm{C}$. A pós o tratamento, os frutos foram transferidos para temperatura ambiente onde permaneceram durante oito dias para favorecer a manifestação dos danos. Avaliaram-se frutos com e sem tratamentos térmicos e químicos. Os danos por frio foram avaliados visualmente sobre as amostras de 30 frutos por tratamento.

\section{Delineamento experimental}

O delineamento experimental utilizado foi o de blocos ao acaso, com nove tratamentos. Os resultados obtidos foram analisados pelo pacote estatístico Statgraphics e comparados entre si utilizando-se o teste Tukey ao nível de 5\%. Para cada tratamento foram utilizadas duas caixas de $18 \mathrm{~kg}$, sendo que cada uma das caixas continha aproximadamente 80 frutos de cerca de $150 \mathrm{~g}$ cada. Em todos os tratamentos foram armazenadas as caixas de frutos em três repetições, perfazendo um total de 54 caixas. Este experimento foi repetido com a mesma estrutura, constituindo-se, portanto, de dois experimentos.

\section{RESULTADOS E DISCUSSÃO}

Na Tabela 1 estão expressos, em porcentagem, os resultados das avaliações de dano por frio decor- 
rentes do armazenamento em baixas temperaturas. Não se verificou diferença estatística entre os tratamentos em ambos os experimentos, excetuando a testemunha que foi mais susceptível em ambas as avaliações, demonstrando que os tratamentos utilizados de alguma forma interferiram no aparecimento de dano por frio. Pelas médias verificou-se que, dentre os tratamentos com água quente, $56^{\circ} \mathrm{C}$ foi o que mais favoreceu a suscetibilidade a danos nos dois experimentos, demonstrando que temperaturas muito elevadas e exposição por um período de tempo longo deixam os frutos mais sensíveis ao aparecimento de danos por frio. SAUCEDO-Veloz et al. (1994) e SAUCEDo-Veloz, (2005), trabalhando com limão Persa, observaram que a diminuição da temperatura de $20^{\circ} \mathrm{C}$ para $11,5^{\circ} \mathrm{C}$ em 1 hora (pré-resfriamento), seguida de um tratamento de acondicionamento a $2,5^{\circ} \mathrm{C}$ durante 2 dias e posterior armazenamento a $1,5^{\circ} \mathrm{C}$ durante 17 dias, como tratamento quarentenário, resultou em menor incidência do frio (25\%) quando comparados com os frutos que foram armazenados diretamente no frio a $1,5^{\circ} \mathrm{C}(100 \%)$. Estes autores demonstraram também que a aplicação de temperaturas elevadas seguidas de frio é benéfica para a manutenção da aparência dos frutos, comprovando os resultados deste trabalho, constatando que a quebra de temperatura reduz a incidência de chilling injury. Neste trabalho verificaram-se, em ambos os experimentos, que temperaturas entre $48 \mathrm{e}$ $54^{\circ} \mathrm{C}$ resultaram em uma menor incidência de danos por frio quando comparadas com a testemunha e o tratamento a $56^{\circ} \mathrm{C}$, portanto, deve-se ter um limite de tolerância à temperatura aplicada, não podendo ultrapassar $54^{\circ} \mathrm{C}$.

Na Tabela 2, onde estão apresentadas as características físicas dos frutos de lima ácida Tahiti submetidas a diferentes tratamentos, pode-se observar que os tratamentos aplicados não interferiram nestes parâmetros, embora se observe diferenças estatísticas entre eles, em função da não uniformi- dade dos frutos no momento da colheita e instalação do ensaio. De acordo com SAUCEDo-Veloz (2008), no México, os frutos de limão Mexicano são colhidos baseando-se no tamanho (35-40 mm de diâmetro), casca lisa, coloração verde brilhante e teor de suco de $45+/-5 \%$. No Brasil, conforme GAYET; SAlvo FILHO (2003), a colheita da lima ácida Tahiti segue os mesmos padrões mexicanos, com diâmetro mínimo de $47 \mathrm{~mm}$ e com casca de aspecto liso para garantir o teor mínimo de suco e cor verde escura garantindo a aparência e o aroma peculiares desse fruto.

A avaliação do ponto de colheita pela cor da casca é uma das formas mais antigas empregadas pela maioria dos produtores. $\mathrm{Na}$ Tabela 3 , primeiro experimento, verificou-se o valor de $C^{*}$ próximo a 60 no último dia de avaliação, indicando que houve um avanço na maturação durante o período de armazenamento. Quando se avaliaram-se os valores de $\mathrm{h}^{\circ}$ observou-se maior heterogeneidade entre os tratamentos do primeiro experimento. Observaram-se que os frutos tratados a $52^{\circ} \mathrm{C}$ foram os que se apresentaram mais verdes, em relação aos demais. Quanto à luminosidade, $\mathrm{L}^{*}, 52^{\circ} \mathrm{C}$ também foi o melhor tratamento, quando comparado aos demais. No segundo experimento, verificou-se que a maior luminosidade, $\mathrm{L}^{*}$, também foi observada no tratamento $52^{\circ} \mathrm{C}$, e a manutenção da coloração verde também ocorreu neste tratamento $\left(52^{\circ} \mathrm{C}\right)$, juntamente com o tratamento bicarbonato de sódio. Tais resultados foram encontrados em relação ao croma $\left(C^{*}\right)$ semelhante ao primeiro experimento. Segundo Gayet; Salvo Filho (2003), a coloração dos frutos, no momento da classificação, varia de verde intenso a verde amarelado, em 5 tipos: $\mathrm{C} 1$, C2; C3, C4 e C5. Verificou-se que neste trabalho houve uma mudança de coloração da casca com o prolongamento do armazenamento, visto que os frutos foram colhidos mais verdes $\left(h^{\circ}\right)$, primeira avaliação, e tenderam para cores mais vívidas como avanço do período de estocagem (última avaliação).

Tabela 1 - Danos por frio em frutos de lima ácida Tahiti submetidos a diferentes tratamentos, em 2 experimentos, Cordeirópolis, SP, 2008. Média de 18 frutos por tratamento. Resultados expressos em porcentagem.

\begin{tabular}{|c|c|c|c|c|c|c|c|}
\hline \multirow{2}{*}{ Tratamento } & \multicolumn{3}{|c|}{ Experimento 1} & \multicolumn{3}{|c|}{ Experimento 2} & \multirow{2}{*}{$\begin{array}{c}\text { Média final } \\
2 \text { exp. }\end{array}$} \\
\hline & $25 / 2$ & $25 / 3$ & Médias & $15 / 4$ & $6 / 5$ & Médias & \\
\hline Testemunha & 38,33 & $16,66 \mathrm{a}$ & 27,49 & 13,66 & $8,00 \mathrm{ab}$ & 10,83 & 19,16 \\
\hline $48^{\circ} \mathrm{C}$ & 15,00 a b c & $8,00 \mathrm{a}$ & 11,50 & $3,33 a$ & $5,33 \mathrm{a}$ & 4,33 & 7,91 \\
\hline $50^{\circ} \mathrm{C}$ & 25,66 & $6,66 \mathrm{a}$ & 16,16 & $6,33 \mathrm{ab}$ & $5,66 \mathrm{a}$ & 5,99 & 11,07 \\
\hline $52^{\circ} \mathrm{C}$ & 24,00 b c d & $8,33 \mathrm{a}$ & 16,16 & 7,66 a b c & $8,33 \mathrm{a} \mathrm{b}$ & 7,99 & 12,07 \\
\hline $54^{\circ} \mathrm{C}$ & $4,33 \mathrm{a} \mathrm{b}$ & $9,00 \mathrm{a}$ & 11,66 & $3,33 \mathrm{a}$ & 3,66 a & 3,49 & 7,57 \\
\hline $56^{\circ} \mathrm{C}$ & $2,33 \mathrm{a}$ & $14,00 \mathrm{~b}$ & 28,16 & $11,00 \mathrm{bc}$ & $3,0 \mathrm{~b}$ & 7,00 & 17,58 \\
\hline Carbonato & 4,00 & $14,33 \mathrm{~b}$ & 9,16 & $4,00 \mathrm{a}$ & $5,33 \mathrm{a}$ & 4,66 & 6,91 \\
\hline Bicarbonato & 32,33 & $18,33 \mathrm{~b}$ & 25,33 & 6,66 a b & $2,00 \mathrm{a}$ & 4,33 & 14,83 \\
\hline Imazalil & 35,66 & $9,00 \mathrm{a}$ & 22,33 & $2,00 \mathrm{a}$ & $6,00 \mathrm{a}$ & 4,00 & 13,16 \\
\hline
\end{tabular}

Médias seguidas de letras distintas nas colunas diferem entre si ao nível de $5 \%$ de probabilidade pelo Teste de Tukey. 


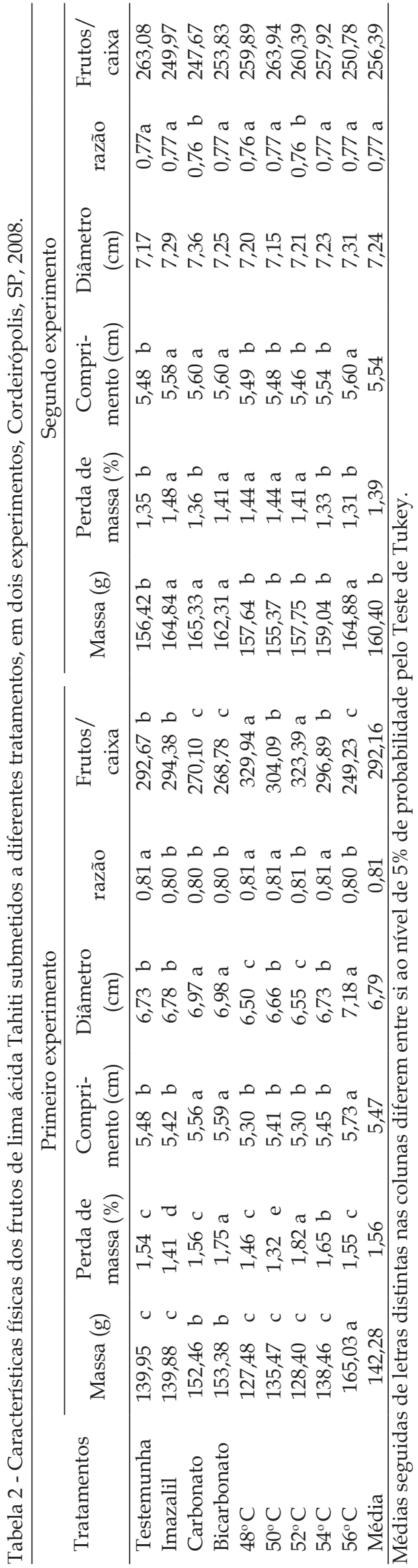

Na lima ácida Tahitia manutenção da cor verde da casca é desejável, durante sua vida útil pós-colheita. Entretanto, os processos de degradação de clorofila e a síntese de carotenoides continuam a ocorrer, mesmo durante o seu armazenamento. Por isso, alguns pesquisadores vêm trabalhando com o intuito de manter a coloração verde da casca deste cultivar. Alguns trabalhos estão sendo feitos utilizando-se, entre outros produtos, o 1-MCP (1-metilciclopropeno) e o GA 3 (ácido giberélico) (BARROs et al., 1991; SILVA; DONADIO, 1997; TAVARES et al., 2004).

Nas Tabelas 4 e 5 estão expressos os resultados obtidos nas avaliações químicas dos frutos, incluindo o rendimento do suco, expresso em função do seu tamanho. No primeiro experimento, último dia de avaliação, apenas os tratamentos testemunha, $48^{\circ} \mathrm{C}$ e carbonato de sódio diferiram estatisticamente dos demais, indicando que, coincidentemente, os frutos estavam menores em relação aos outros quando se procedeu à montagem aleatória dos frutos para cada tratamento. No segundo experimento verificou-se maior homogeneidade entre os frutos com relação ao rendimento de suco.

Pelos resultados obtidos das avaliações dos parâmetros químicos, os frutos colhidos no mesmo ponto de maturação, levando-se em consideração o teor de SS e a coloração da casca, apresentaram resultados de SS semelhantes em todos os tratamentos avaliados, fato constatado pelas análises deste parâmetro onde não se verificou diferença significativa ao nível de 5\% pelo teste de Tukey. O mesmo resultado foi constatado quando se corrigiu o valor de SS para -BRIX (Tabela 5), logo, os tratamentos aplicados não interferiram na qualidade interna dos frutos. Em trabalho realizado por SAUCEDO-VELOZ (2008), com limão Mexicano, foi verificado teor de ${ }^{\circ}$ Brix em torno de 8,0, e constatado que a aplicação externa de ácido giberélico, associado ou não a ceras aplicadas em pós-colheita, não interfere na qualidade interna dos frutos. Neste trabalho foram feitas as mesmas observações em relação aos parâmetros intrínsecos, cujos teores de ${ }^{\circ}$ Brix encontrados situaram-se entre 8 e 9 , em ambos os experimentos.

O teor de ácidos dos citros é obtido pela acidez total, medida por titulação com hidróxido de sódio de todos os ácidos presentes. Neste trabalho, para o parâmetro acidez total, verificou-se também um comportamento semelhante para todos os tratamentos e nos 2 experimentos, não havendo diferenças significativas entre um tratamento e outro. Os valores médios de acidez total ficaram em torno de $5 \mathrm{mg} / 100 \mathrm{~mL}$ de suco nos dois experimentos. Estes valores foram menores que os encontrados por SAUCEDo-Veloz (2008), em limão Mexicano (8 $\mathrm{mg} / 100 \mathrm{~mL}$ de suco), indicando que a lima ácida Tahiti aqui estudada apresentou menor acidez que a cultivar mexicana. 


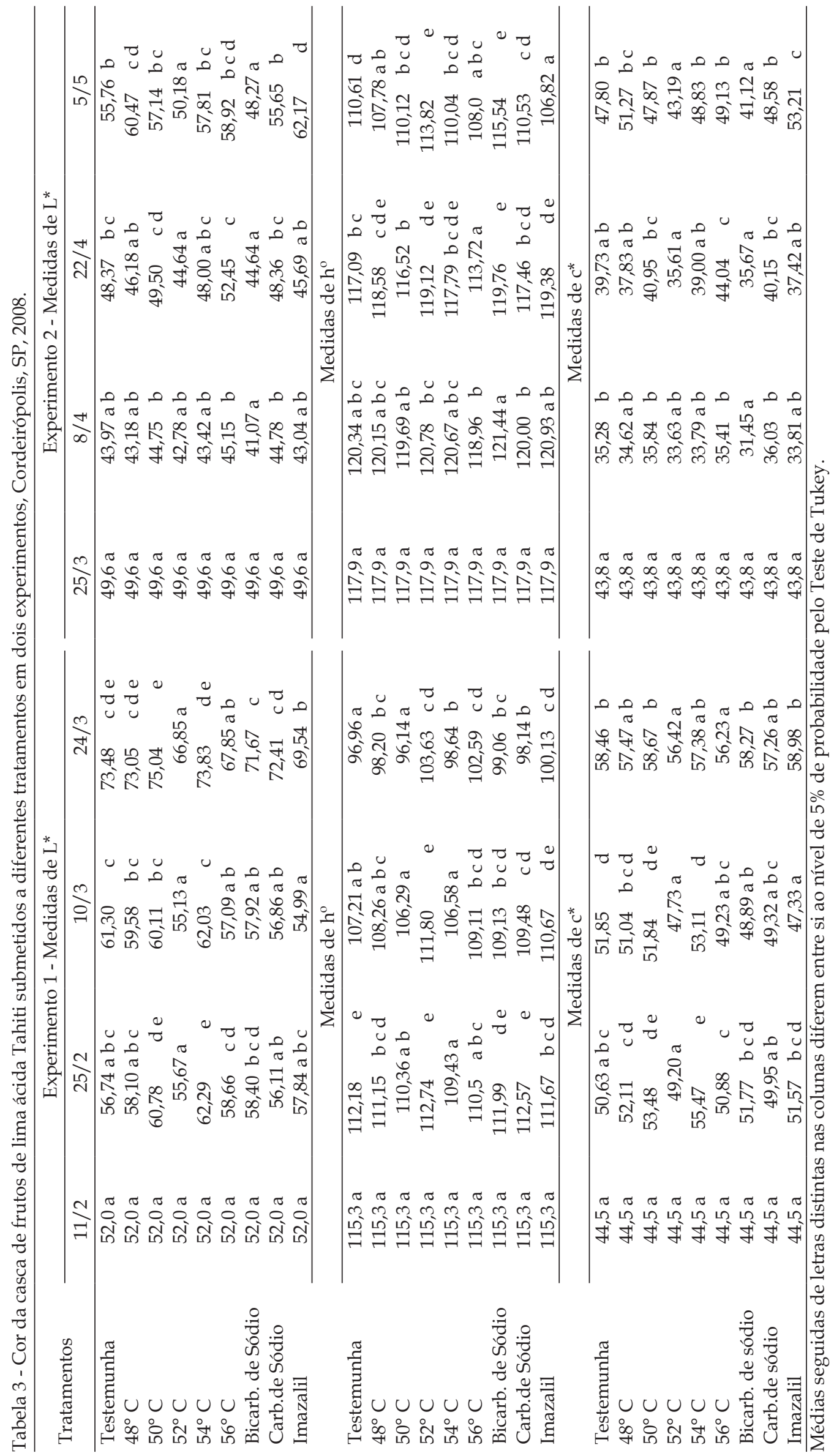




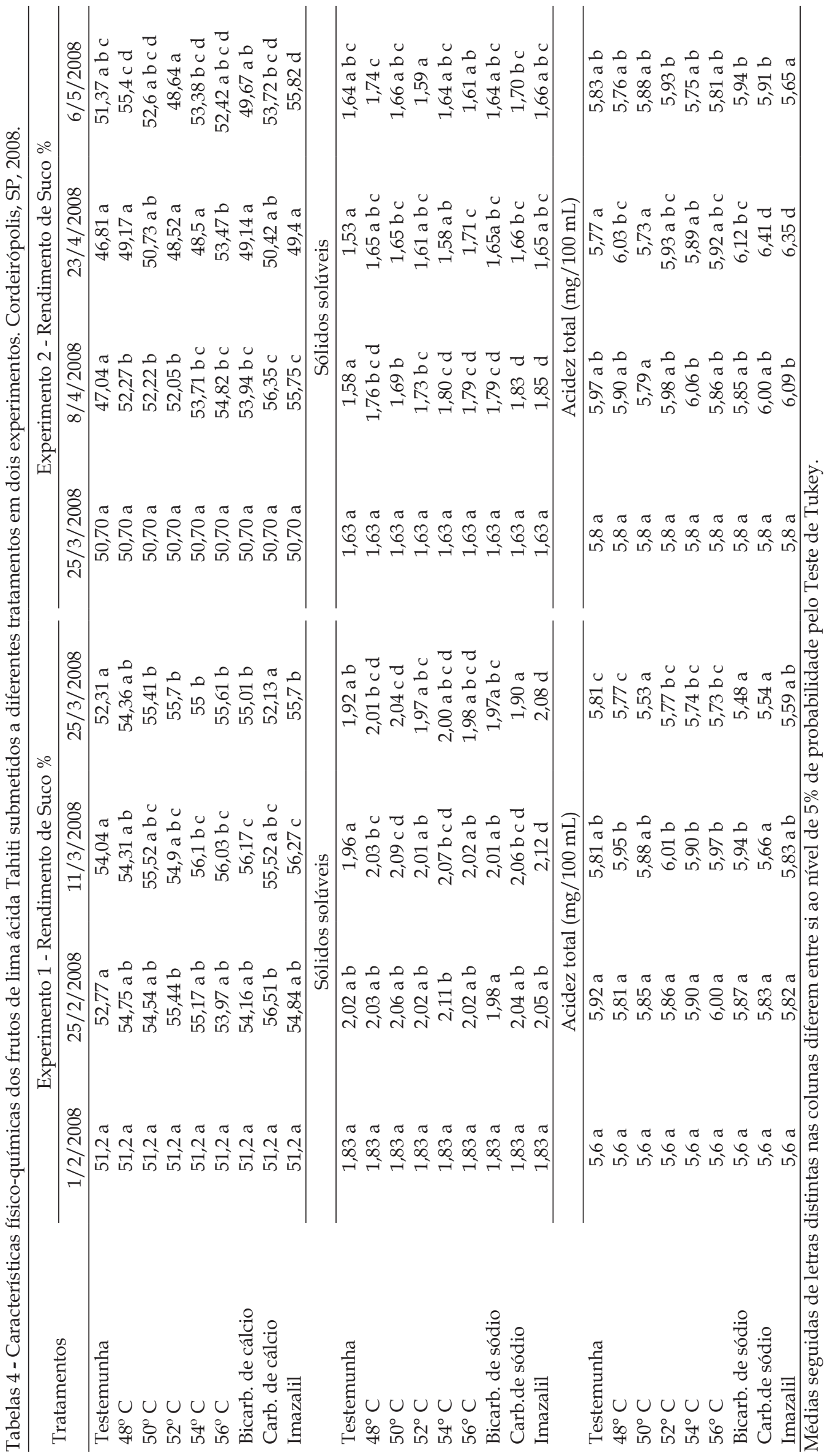




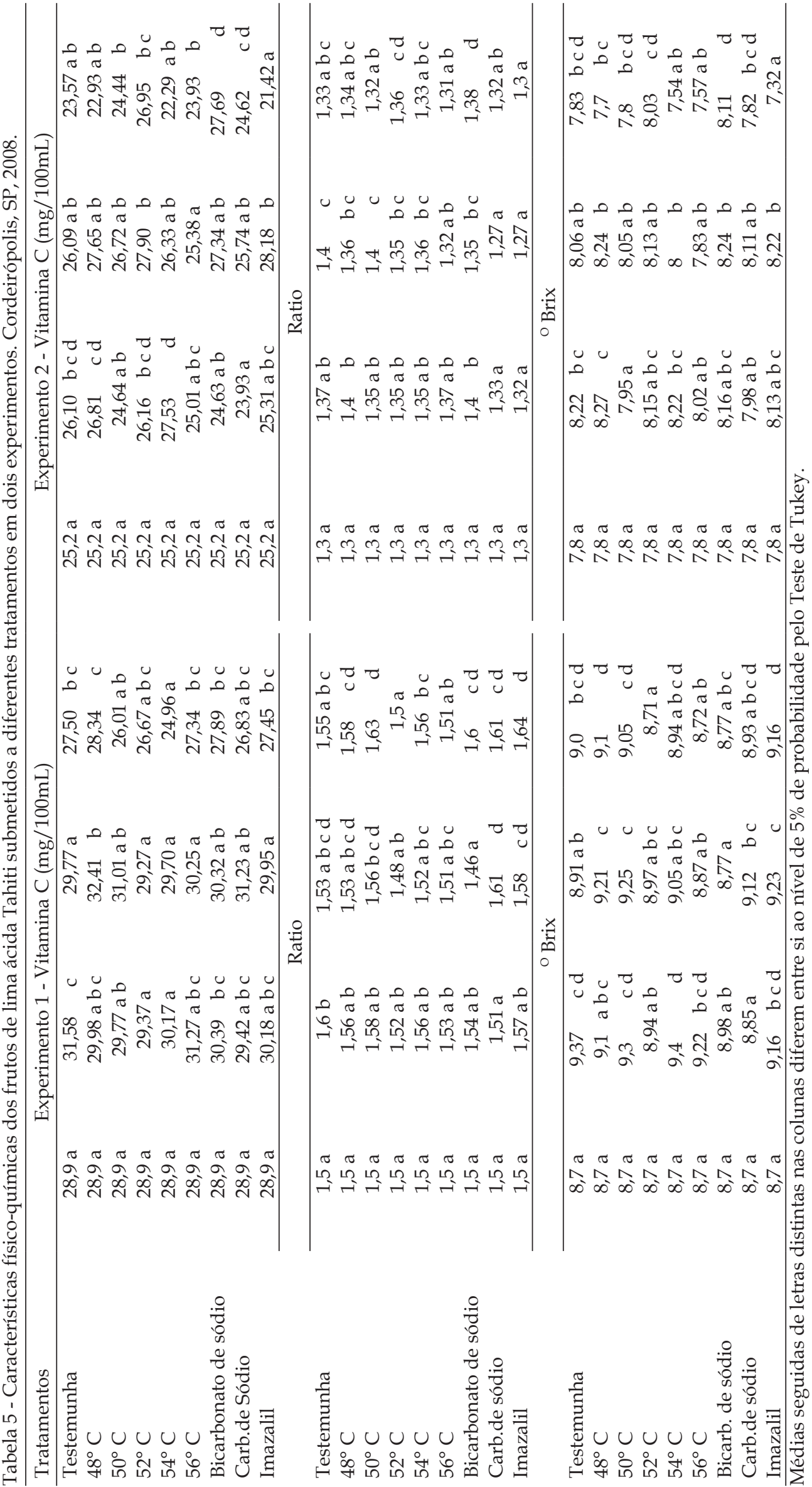




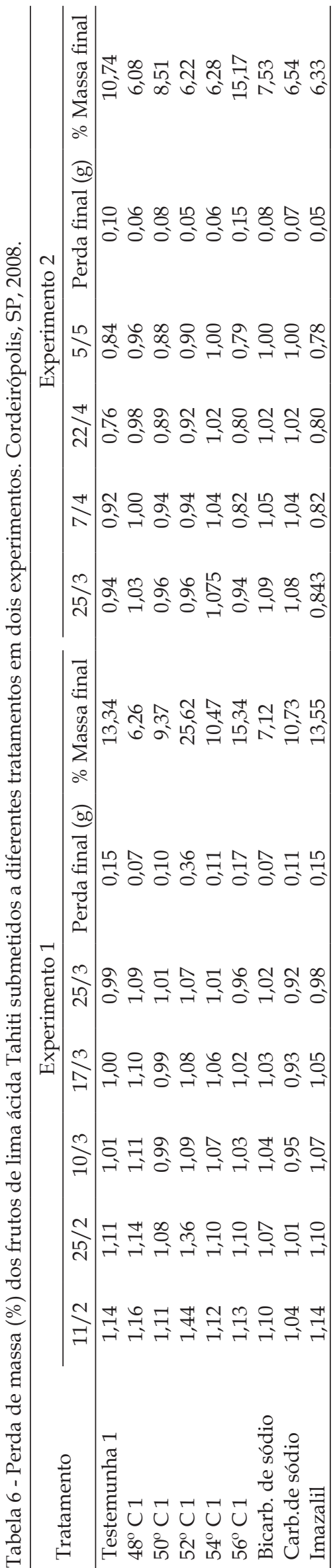

A quantificação da relação entre o teor de sólidos solúveis e acidez total (ratio) está relacionada com o balanço entre açúcares e ácidos presentes nos frutos, sendo um importante atributo de indicação do sabor (KLUGE et al., 2002). Analisando os valores de ratio, observou-se um ligeiro aumento no final dos dois experimentos, sendo o menor valor do primeiro experimento igual a 1,5 e o maior igual a 1,64 . No segundo experimento os valores variaram de 1,3 a 1,38 , o que sugere o pequeno aumento na degradação de açúcares eácidos, embora não se tenha verificado diferenças estatisticamente significativas entre os tratamentos aplicados.

Com relação à quantificação de vitamina $C$, presentes em todas as frutas e destacando o ácido ascórbico como predominante nos cítricos (entre $0,04 \mathrm{e} 0,08 \%$ ), verificou-se que nos dois experimentos ocorreu uma diminuição do teor deste parâmetro no último dia de avaliação, e sem diferenças significativas entres os tratamentos (Tabela 5). Segundo Chitarra; Chitarra (2005), o teor de vitamina C tende a diminuir com o avanço da maturação e com o armazenamento devido à ação direta da enzima ácido ascórbico oxidase (ascorbinase), ou pela ação de enzimas oxidantes como a peroxidase.

Avaliando os valores de perda de massa, decorrente da perda de água pelas frutas pelo processo de transpiração (Tabela 6), primeiro experimento, verificou-se valores mais elevados para o tratamento $52^{\circ} \mathrm{C}$. Entretanto, salienta-se que este valor final ( $25 \%$ de perda de massa) foi obtido devido à retirada antecipada de frutos, durante o experimento, em decorrência do aparecimento de doenças. Avaliandose todos os resultados do primeiro experimento, verificaram-seque o tratamento $48^{\circ} \mathrm{C}$ foi o que menos propiciou perda de água durante o armazenamento a $10^{\circ} \mathrm{C}$ e $90 \%$ UR. No segundo experimento (Tabela 6), a perda de massa foi maior no tratamento a $56^{\circ} \mathrm{C}$, devido também ao aparecimento de enfermidades, seguido da testemunha. Conformeresultados, todos os demais tratamentos se mostraram benéficos, com redução da perda de água por transpiração, quando comparados com os frutos testemunha.

As substâncias pécticas são as responsáveis pela firmeza da polpa (textura), uma vez que são os principais componentes das paredes celulares. Com o avanço da maturação essas substâncias se tornam solúveis promovendo o amolecimento da polpa (KLuge et al., 2002). Para se avaliar a firmeza da fruta utiliza-se o penetrômetro cuja leitura indica o grau de resistência da polpa e os resultados podem ser expressos em libras, kg ou Newton. Neste trabalho, os valores obtidos das avaliações de resistência da polpa (Tabela 7) no experimento 1 foram expressos em Newton. Constatou-se maior resistência da textura nos frutos tratados termicamente e com bicarbonato de sódio. Os frutos testemunha e tratados 

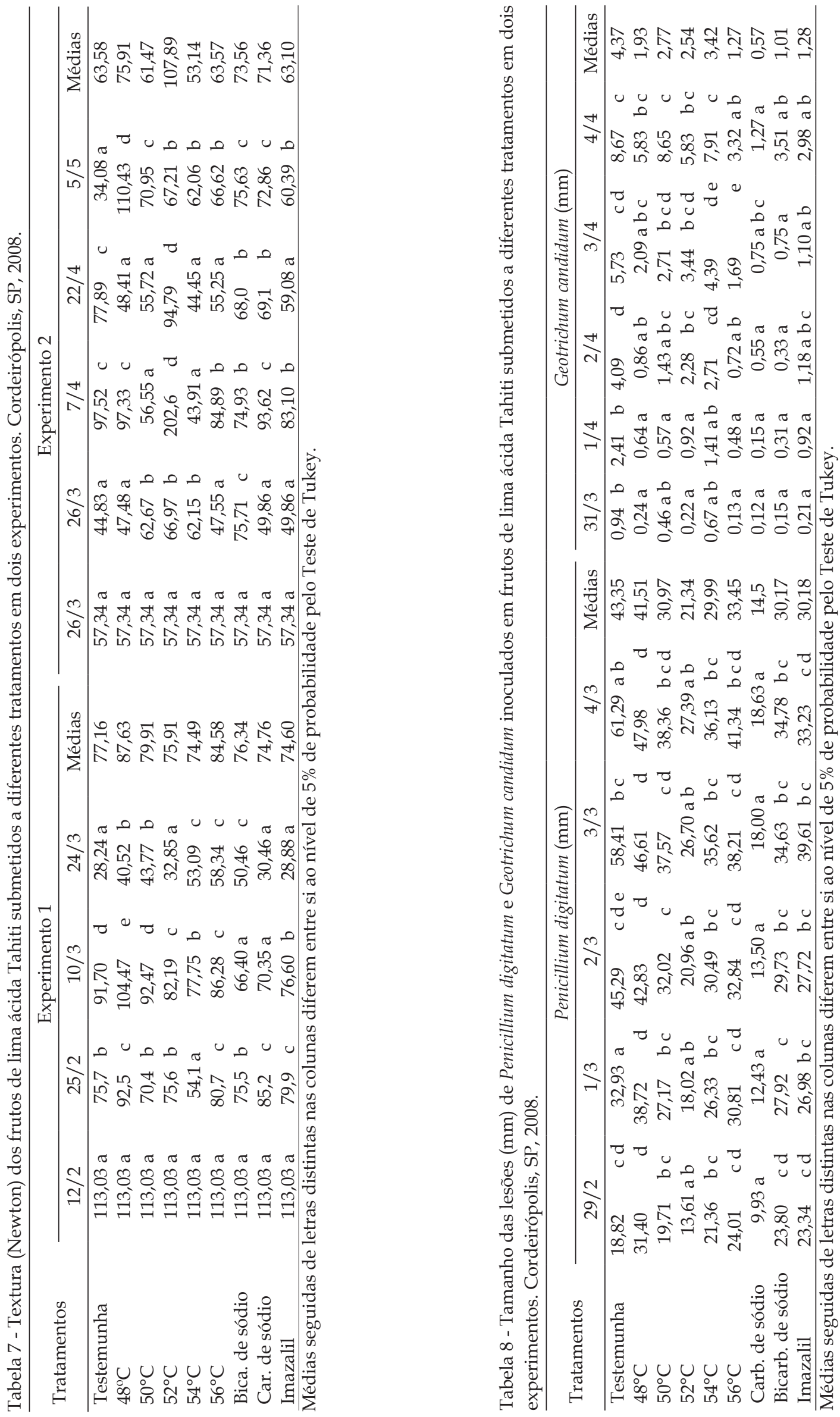
com imazalil foram aqueles que se apresentaram mais amolecidos. No segundo experimento, os frutos testemunha também foram os que estavam mais amolecidos.

Na Tabela 8 estão descritos os resultados obtidos com a inoculação de patógenos. Para P. digitatum, os frutos testemunha foram os mais afetados pelo fungo, seguidos dos frutos do tratamento térmico a $48^{\circ} \mathrm{C}$. Verificou-se que o carbonato de sódio e o tratamento térmico a $52^{\circ} \mathrm{C}$ foram os mais eficientes, resultando em menores incidências do patógeno, superando inclusive o tratamento com imazalil, fungicida de conhecida eficiência no controle de P. digitatum. Williams et al. (1994), averiguaram o efeito do aquecimento térmico na pré-estocagem de laranjas Valência. Segundo os autores, houve uma redução acentuada no número de esporos de $P$. digitatum e $P$. italicum nos frutos tratados previamente com água quente a $45^{\circ} \mathrm{C}$ durante 42 minutos, confirmando os resultados obtidos neste trabalho, embora mudando o grau de temperatura da água de aquecimento e o tempo de exposição. Segundo os mesmos autores, os tratamentos térmicos na pré-estocagem poderiam ser uma alternativa favorável aos produtos químicos para o controle de pragas e doenças. SMILANICK et al. (2006), também verificaram em seus trabalhos um controle de 50\% de desenvolvimento de $P$. digitatum quando frutos de limões foram imersos em água a $49^{\circ} \mathrm{C}$ e, adi- cionando tiabendazol à água aquecida houve um controle de quase $100 \%$. Quanto ao uso de carbonato de sódio 3\%, PALOU et al. (2001), verificaram sua eficácia no controle de Penicillium em citros tratados por imersão durante 1,5 minutos em solução com água a $45^{\circ} \mathrm{C}$. Embora o carbonato de sódio, neste trabalho tenha sido aplicado em solução de água em temperatura ambiente, verificou-se um bom controle por este produto alternativo.

Na Tabela 8 estão apresentados também os resultados dos experimentos de inoculação com Geotrichum candidum. Verificou-se, pelas médias, que os frutos testemunha foram os mais afetados, seguido do tratamento $54^{\circ} \mathrm{C}$. Pelos valores das médias, verificou-se também um controle semelhante entre todos os demais tratamentos, sendo que o carbonato de cálcio se apresentou muito promissor no controle deste patógeno, seguido dos tratamentos químico com imazalil e do aquecimento térmico.

Considerando os fungos oriundos do campo (Tabela 9), verificou-se que, no segundo experimento, o fungicida imazalil foi o que proporcionou melhores resultados no controle de $P$. digitatum. Os demais tratamentos apresentaram comportamento semelhantes, excetuando-se o tratamento a $56^{\circ} \mathrm{C}$, cuja manifestação deste patógeno foi maior que nos demais, inclusive que a testemunha. No primeiro experimento, a manifestação da enfermidade foi bastante homogênea entre os tratamentos.

Tabela 9 - Crescimento de patógenos dos frutos de lima ácida Tahiti referente aos tratamentos por imersão estudados no primeiro e segundo experimentos. Resultados expressos em porcentagem. Caixas com 80 frutos. 2008.

\begin{tabular}{|c|c|c|c|c|c|c|c|c|c|c|}
\hline \multirow[b]{2}{*}{ Fungos } & \multicolumn{10}{|c|}{ Experimento 1} \\
\hline & Data & Test. & $48^{\circ} \mathrm{C}$ & $50^{\circ} \mathrm{C}$ & $52^{\circ} \mathrm{C}$ & $54^{\circ} \mathrm{C}$ & $56^{\circ} \mathrm{C}$ & $\begin{array}{c}\text { Bicarb. } \\
\text { de sódio }\end{array}$ & $\begin{array}{l}\text { Carb. de } \\
\text { sódio }\end{array}$ & Imazalil \\
\hline \multirow{4}{*}{ Phomopsis citri } & $20 / 2$ & 3,75 & 12,50 & 20 & 0 & 10 & 11,25 & 6,25 & 10 & 1,25 \\
\hline & $25 / 2$ & 2,50 & 0 & 4 & 0 & 3,75 & 1,25 & 0 & 0 & 1,25 \\
\hline & $10 / 3$ & 0 & 7,50 & 2,50 & 0 & 2,50 & 2,50 & 10 & 5 & 10 \\
\hline & $24 / 3$ & 1,25 & 1,25 & 7,50 & 5 & 0 & 7,50 & 2,50 & 2,50 & 0 \\
\hline Média total & & 1.87 & 5,31 & 8,5 & 1,25 & 4,06 & 5,62 & 4,68 & 4,37 & 3,12 \\
\hline \multirow{4}{*}{ P. digitatum } & $20 / 2$ & 2,50 & 0 & 0 & 0 & 0 & 0 & 0 & 1,25 & 0 \\
\hline & $25 / 2$ & 1,25 & 1,25 & 0 & 1,25 & 0 & 0 & 6,25 & 0 & 0 \\
\hline & $10 / 3$ & 0 & 7,50 & 6,25 & 2,50 & 7,50 & 2,50 & 1,25 & 8,75 & 8,75 \\
\hline & $24 / 3$ & 7,50 & 0 & 2,50 & 2,50 & 1,25 & 0 & 1 & 3 & 0 \\
\hline Média total & & 2,81 & 2,18 & 2,18 & 1,56 & 2,18 & 0,65 & 2,12 & 3,25 & 2,19 \\
\hline \multirow[t]{2}{*}{ Fungos } & \multicolumn{10}{|c|}{ Experimento 2} \\
\hline & $7 / 4$ & 6,25 & 3,75 & 6,25 & 6,75 & 1,25 & 6,25 & 2,50 & 0 & 0 \\
\hline \multirow[t]{2}{*}{ Phomopsis citri } & $22 / 4$ & 0 & 2,50 & 3,75 & 0 & 0 & 0 & 0 & 0 & 1,25 \\
\hline & $5 / 5$ & 2,50 & 3,75 & 15 & 12,50 & 20 & 17,50 & 37,50 & 78,75 & 2,50 \\
\hline \multirow[t]{2}{*}{ Média Total } & & 2,91 & 3,33 & 8,33 & 6,41 & 7,08 & 7,91 & 13,33 & 26,25 & 1,25 \\
\hline & $7 / 4$ & 0 & 0 & 0 & 0 & 0 & 1,25 & 0 & 0 & 0 \\
\hline \multirow[t]{2}{*}{ P. digitatum } & $22 / 4$ & 3,75 & 1,25 & 0 & 2,50 & 0 & 6,25 & 2,50 & 1,25 & 0 \\
\hline & $5 / 5$ & 1,25 & 0 & 2,50 & 2,50 & 1,25 & 3,75 & 0 & 1,25 & 0 \\
\hline Média total & & 1,66 & 0,41 & 0,83 & 1,66 & 0,41 & 3,75 & 0,83 & 0,83 & 0 \\
\hline
\end{tabular}


Com relação ao aparecimento de Phomopsis citri, fungo responsável pela podridão peduncular (Tabela 9), verificaram-se que, no primeiro experimento, os frutos tratados a $52^{\circ} \mathrm{C}$ foram os menos susceptíveis ao ataque desses patógenos, seguidos dos frutos testemunha. No segundo experimento (Tabela 9), os frutos tratados com $52^{\circ} \mathrm{C}$ estiveram entre aqueles que manifestaram menos os sintomas da doença. Tanto no primeiro, como no segundo experimento, o fungicida imazalil demonstrou bons resultados no controle de P. citri. Em nenhum dos tratamentos ocorreu a manifestação de G. candidum.

\section{CONCLUSÕES}

Os tratamentos alternativos (bicarbonato ou carbonato de sódio) ou químico com imazalil aplicados não interferem nos parâmetros internos e externos de frutos de lima ácida Tahiti. De todos os tratamentos alternativos avaliados visando à substituição dos fungicidas de sínteses convencionais, a utilização de $52^{\circ} \mathrm{C}$ e de carbonato de cálcio são os que mais se destacam no controle de doenças pós-colheita, principalmente do mofo verde, causado por $P$. digitatum.

Para o controle de danos por frio, a aplicação de carbonato de sódio mostra-se bem efetiva, seguido dos tratamentos térmicos, nas faixas de 48 a $54^{\circ} \mathrm{C}$, o que permite concluir que o uso de termoterapia previne o aparecimento de chilling injury em limas ácidas Tahiti.

\section{AGRADECIMENTOS}

Este trabalho de pesquisa foi realizado com o apoio financeiro da Fundação de Apoio à Pesquisa do Estado de São Paulo (FAPESP).

\section{REFERÊNCIAS}

BARROS, S.A; RODRIGUES, J.D.; PEDRAS, J.F. Efeito do ácido giberélico e do uniconazole na fisiologia pós-colheita de limão "Tahiti" (Citrus latifólia Tanaka). Revista Brasileira de Fruticultura, v.13, p.223-226, 1991.

BEN-YEHOSHUA, S.; KIM, J.J.; SHAPIRO. Curing of citrus fruits. Application and mode of action. In: FELLMAN, G.K. (Ed.). Proceedings of the Fifth Internacuinal Controlled Atmosphere Research Conference, 1989, Wenaldee, WA. Washington: Washington State University Public, 1989, v.2, p.179-196.

BEN-YEHOSHUA, S.; RODOV, V.; FANG, D.Q.; KIM, J.J. Performed antifungal compounds of citrus fruit: effects of preharvest treatment with heat and growth regulators. Journal Agricultural Food Chemistry, v.43, p.1062-1066, 1995.

BEN-YEHOSHUA, S.; PERETZ, J.; RODOV, V.; NAFUSSI, B.; YEKUTIELI, O.; WISEBLUM, A.; REGEV, R. Postharvest comercial application of hot water treatments to control decay in kunquat fruit: Report to the Israel Citrus Board. 1997.

CHITARRA, M.I.F.; CHITARRA, A.B. Pós-colheita de frutas e hortaliças. 2.ed. Lavras: Editora Universidade Federal de Lavras, 2005. 416p.

CUQUERELLA, J.; NAVARRO, P. Estado actual de la frigoconservación de los cítricos. Fruticultura Profesional, n.25, p.122-129, 1989.

DI GIORGI, F.; IDE, B.Y.; DIB, K.; MARCH, R. J.; TRIBONI, H. de R.; WAGNER, R.L. Contribuição ao estudo do comportamento de algumas variedades de citros e suas implicações agroindustriais. Laranja, v.11, n.2, p.567-612, 1990.

GAYET, J.P.; SALVO FILHO, A. Colheita e beneficiamento. Lima ácida Tahiti. Campinas: Instituto Agronômico, 2003. 162p.

GRIERSON, W.; BEN-YEHOSHUA, S. The storage of citrus fruits. In: WARDOWSKY, W.F.; NAGY, S.; GRIERSON, W. (Ed.). Fresh citrus fruits. Wesport: Eds. Avi Publishing, 1986. Cap.20, p.479-500.

KLUGE, R.A.; NACHTIGAL, J.C.; FACHINELLO, J.C.; BILHALVA, A.B. Fisiologia e manejo pós-colheita de frutas de clima temperado. 2.ed. Campinas, 2002. 214p.

NASCIMENTO, L.M.; SANTOS, E.J.; LEONEZI, A.L. Eficiência da aplicação de diferentes doses de fungicidas em lima ácida Tahiti, laranja Pêra e tangor Murcott para o controle de Penicillium digitatum. Revista Iberoamericana de Tecnologia Postcosecha, v.7, n.1, p.41-47, 2005.

PALOU, L.; SMILANICK, J.L.; USALL, J.; VIÑAS, I. Control of postharvest blue and Green molds of oranges by hot water, sodium carbonate, and sodium bicarbonate. Plant Disease, v.85, n.4, p. 371-376, 2001.

POZZAN, M.A. Comportamento e tratamentos de frutos cítricos em pós-colheita. Revista Laranja, v.18, n.1, p.189-204, 1997.

REDD, J.B.; HENDRIX JUNIOR, C.M.; HENDRIX, D.L. Quality control manual for citrus processing plants. Flotida: Intercit, 1986. v.1, 250p.

SAUCEDO-VELOZ, C. Sistemas de manejo post-cosecha de limas ácidas. In: SEMINARIO INTERNACIONAL POS-COSECHA DE CITRICOS, 2., 2005, Concordia - Entre Rios. Actas. Concordia - Entre Rios: INTA, 2005. p.65-69.

SAUCEDO-VELOZ, C. Tópicos em qualidade e póscolheita de citros. Campinas: Instituto Agronômico, 2008. 285p. 
SAUCEDO-VELOZ, C.; ARANA ERRASQUIN, R.; ARÉVALO GALARZA, M.L. Aplicación de tratemientos cuarentenários com temperaturas de refrigeración sobre La calidad de limón Persa (Citrus latifólia Tan.). In: REUNIÓN ANUAL DE LA SOCIEDAD INTERAMERICANA DE HORTICULTURA TROPICAL, 40., 1994, Campeche. Memoria de Resúmenes. Campeche: Sociedad Interamericana de Horticultura Tropical, 1994. p.108.

SILVA, J.A.A; DONADIO, L.C. Reguladores vegetais na citricultura. Jaboticabal: UNESP, 1997. 38p. (Boletim Citrícola, 3).

SMILANICK, J.L.; MANSOUR, M.F.; SORENSON, D. Pre and postharvest treatments to control green mold of citrus fruit during ethylene degreening. Plant Disease, v.90, n.1, p.89-96, 2006.
TAVARES, S.; CASTRO, P.R.C.; KLUGE, R.A.; JACOMINO, A.P. Efeito do ácido giberélico e sua combinação com 1-metilciclopropeno e amono etoxivinilglicina, na qualidade pós-colheita da lima ácida "Tahiti". Laranja, v.25, n.1, 2004 .

WILLIAMS, M.H.; BROWN, M.A.; VESK, M.; BRADY, C. Effect of postharvest heat treatments on fruit quality, surface structure, and fungal disease in Valencia oranges. Australian Journal of Experimental Agriculture, v.34, n.8, p.1183-1190, 1994.

Recebido em 2/9/11

Aceito em 8/4/13 